\title{
LXIII. The action of uniform electric and magnetic fields on moving electrons
}

\section{A.H. Bucherer D.Sc.}

To cite this article: A.H. Bucherer D.Sc. (1907) LXIII. The action of uniform electric and magnetic fields on moving electrons, Philosophical Magazine Series 6, 13:78, 721-721, DOI: $10.1080 / 14786440709463650$

To link to this article: http://dx.doi.org/10.1080/14786440709463650

曲 Published online: 16 Apr 2009.

Submit your article to this journal $₫$

Џll Article views: 1

Q View related articles $₫$ 
by Hallwachs, in addition to the work of his predecessors, there seems little doubt that the simpler idea of changes in the absorptive power of electrified double-layers and other films of gases of great density near the surface of the metals, is the probable cause of fatigue. And the experiments described in this paper show no reason for not accepting the same hypothesis to explain the changes occurring in this type of secondary radiation.

I take great pleasure in thanking Professor Thomson for his advice and for his many courtesies to me during my visit to the Cavendish Laboratory.

Cavendish Laboratory, Cambridge, March 1907.

LXIII. The Action of Uniform Electric and Magnetic Fields on. Moving Electrons. By A. H. Bucherer, D.Sc., Bonn University*.

$\mathrm{N}$ my paper on a new principle of relativity in electro1 magnetism (Phil. Mag., April), in which I have calculated the forces acting on moving electrons in the uniform fields of electromagnets and of condensers, I have omitted to call special attention to the circumstance that the expressions obtained do not apply to all kinds of uniform fields. In fact, as will be evident at once from the reasoning adopted by me, l.c., the forces on the electrons primarily depend on the distribution of electric and magnetic masses, and indirectly only on the intensities of the fields in which they are moving. Thus electrons moving in various uniform fields of the same intensity will in general experience different forces if these fields are due to different distributions of electric and magnetic masses, special care being requisite with solenoids which must be replaced by equivalent magnetic shells.

Closely connected with this is another important consequence. Let an electron move in the uniform superimposed fields $\mathbf{H}_{0}{ }^{\prime}$ and $\mathbf{H}_{0}^{\prime \prime}$ of two electromagnets. Then, to find the resultant force, it is not permissible to substitute the resultant field $\mathbf{H}_{0}^{\prime \prime \prime}$ in the expression given by me. For evidently $\frac{\mathrm{VH}_{0}{ }^{\prime} \mathbf{u}}{1-\frac{u^{2}}{v^{2}} \cos ^{2}\left(\mathbf{H}_{0}{ }^{\prime} \mathbf{u}\right)}+\frac{\mathrm{VH}_{0}{ }^{\prime \prime} \mathbf{u}}{1-\frac{u^{2}}{v^{2}} \cos ^{2}\left(\mathbf{H}_{0}{ }^{\prime \prime} \mathbf{u}\right)} \neq \frac{\mathrm{VH}_{0}{ }^{\prime \prime} \mathbf{u}}{1-\frac{u^{2}}{v^{2}} \cos ^{2}\left(\mathbf{H}_{0}{ }^{\prime \prime \prime} \mathbf{u}\right)}$.

I am preparing experiments with Becquerel rays in order to test the formulæ derived by me from the principle of relativity.

Bonn University, April 1907.

* Communicated by the Author.

Phil. Mag. S. 6. Vol. 13. No. 78. June 1907. 